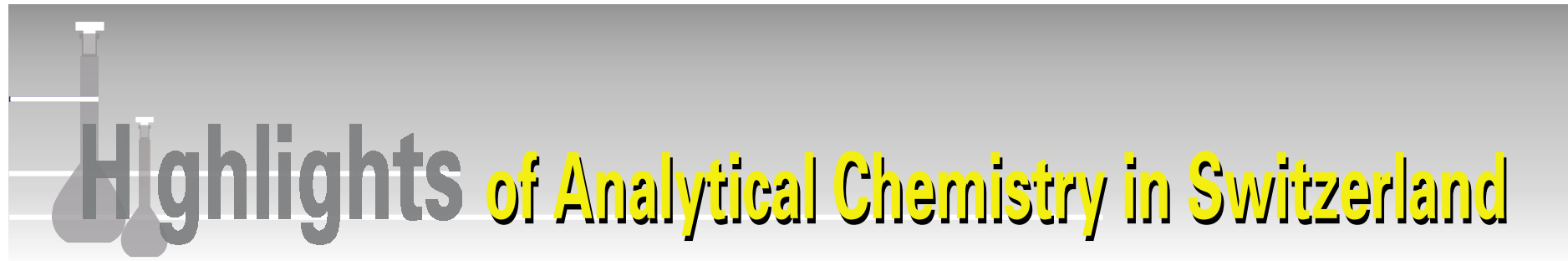

\section{Impact of the Altitude of Pasture on Fatty Acid Composition of Milk}

\section{Marius Collomb and Karin Wehrmüller}

${ }^{*}$ Correspondence: K. Wehrmüller, Agroscope Liebefeld-Posieux Research Station ALP, Schwarzenburgstrasse 161, CH-3003 Bern, Tel.: +41 3132530 31, Fax: +41 31 32382 27, E-mail: karin.wehrmueller@alp.admin.ch

Keywords: CLA isomers · Fatty acids · Highlands · Milk · MUFA · Omega-3 fatty acids - PUFA

Several publications have shown that milk from the lowlands, mountains and highlands have different fatty acid compositions. Milk production and processing is an important economic sector in the mountain areas of Switzerland. Better knowledge of the quality of milk fat and its influencing factors can lead to the development of products in these areas with a higher added value which could also be communicated to consumers.

The classical ISO method for the determination of the composition of fatty acids (i.e. gas-liquid chromatography of methylester derivatives) allows only the determination of 18 fatty acids. With a high-resolution gas chromatographic method it is possible to quantify about 70 fatty acids. Conjugated linoleic acid isomers (CLAs) are analyzed by silver-ion $\left(\mathrm{Ag}^{+}\right)$-HPLC .

Milk fat from the highlands $(1275-2120 \mathrm{~m})$ and mountains (900-1210 m) contained a smaller amount of saturated- and more monounsaturated fatty acids (MUFA). A nearly constant increase with increasing altitude is seen for polyunsaturated fatty acids (PUFA), linoleic acid (C18:2) and the sum of CLA isomers. The essential omega-3 fatty acids are high in milk fat from the highlands. Investigation on the influence of the seasons (summer and winter) in mountain regions show that summer milk had a signifi-

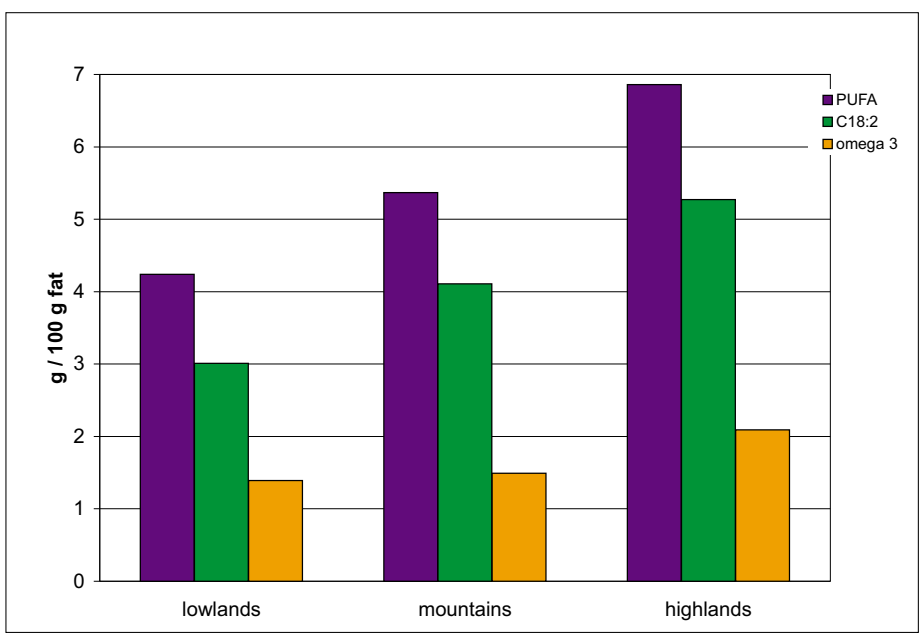

Fatty acid composition of milk from different altitudes cantly lower concentration of saturated fatty acids and significantly higher contents of MUFA, PUFA and CLA.

The differences in the composition of fatty acids of milk fats depending on the altitude are likely to be due to botanical differences. It was, however, shown that the increasing CLA content is not due to the altitude, but rather coincidentally correlates with it. It is also hypothesized that the increase e.g. in the CLA content of alpine summer milk is mainly due to pasture feeding and the absence or low amounts of concentrates. These effects could be also amplified by specific body fat mobilization in cows with alpinespecific hypoxia as well as reduced ruminal biohydrogenation due to energy shortage or secondary plant ingredients that inhibit the hydrogenating microorganisms in the rumen

Milk fat from highlands appears interesting from the nutritional point of view because of the great reduction of saturated and the increase of polyunsaturated fatty acids. This could provide a positive opportunity for the promotion of alpine milk as healthy products.

Received: December 4, 2007

\section{References}

M. Collomb, U. Bütikofer, R. Sieber, B. Jeangros, J.O. Bosset, Int. Dairy J. 2002, 12, 649 .

M. Collomb, R. Sieber, U. Bütikofer, Lipids 2004, 39, 355

W. Bisig, P. Eberhard, M. Collomb, B. Rehberger, Lait 2007, 87, 1.

M. Collomb, W. Bisig, U. Bütikofer, R. Sieber, M. Bregy, L. Etter, J. Dairy Res. 2007, submitted.

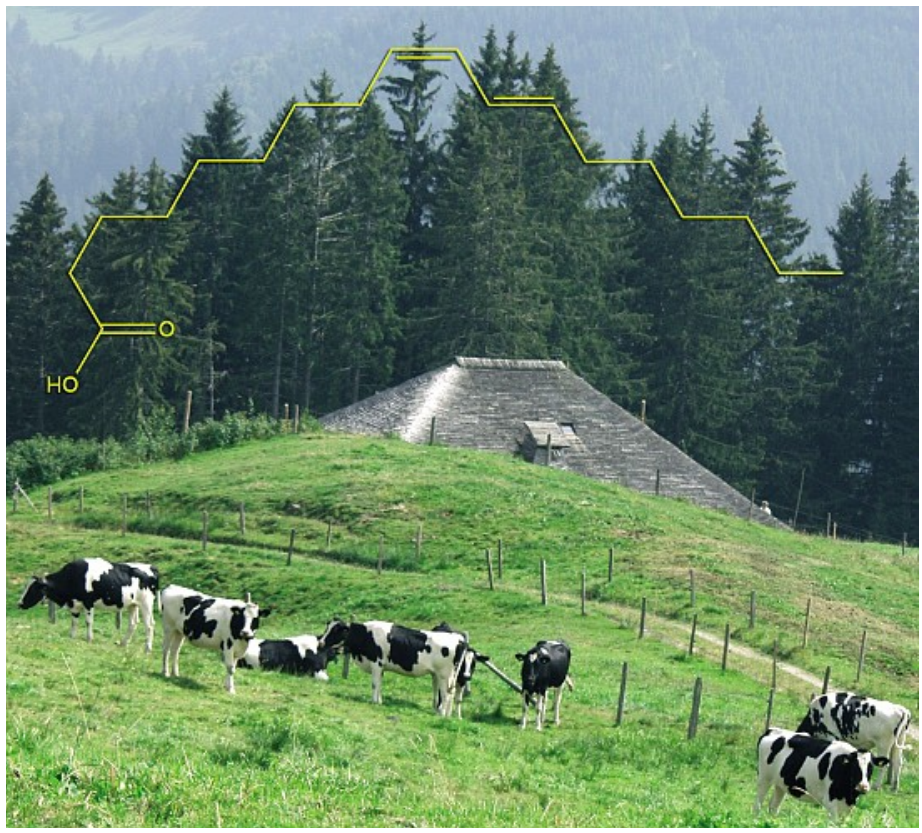

Happy cows in the Swiss highlands. The molecule shown is cis-9,trans-11 octadecadienoic acid, the most important CLA isomer in cow milk. 